\title{
Long-term Outcome after Liver Resection for Hepatocellular Carcinoma Larger than $10 \mathrm{~cm}$
}

\author{
Pierre Allemann • Nicolas Demartines • \\ Hanifah Bouzourene $\cdot$ Adrien Tempia • \\ Nermin Halkic
}

Published online: 28 November 2012

(C) Société Internationale de Chirurgie 2012

\begin{abstract}
Background The purpose of the present study was to analyze long-term survival and disease-free survival after liver resection for giant hepatocellular carcinoma (HCC) $\geq 10 \mathrm{~cm}$ compared to $\mathrm{HCC}<10 \mathrm{~cm}$ in diameter. The surgical approach in the treatment of giant HCC may achieve long-term survival and disease-free survival comparable to treatment of smaller lesions.

Methods This retrospective analysis was a monocentric study conducted in a tertiary university center. It included 101 patients from 114 consecutive liver resections for HCC, separated into two groups: those with tumors less than $10 \mathrm{~cm}$ in diameter (small HCC; $n=79$ ) and those with tumors larger than $10 \mathrm{~cm}$ (giant HCC; $n=22$ ). The main outcome measures were overall five-year survival, five-year disease-free survival, recurrence rate, perioperative mortality at 30 days, surgical complication rate, and re-intervention rate.

Results The two groups were homogeneously distributed, apart from cirrhosis, which was found more frequently in the group with small HCC (77 vs. $41 \% ; p=0.0013$ ). Both median survival (24 vs. 27 months; $p=0.0085)$ and overall 5 -year survival (21 vs. $45 ; p=0.04$ ) were significantly poorer in the small HCC group compared to the
\end{abstract}

P. Allemann · N. Demartines $(\square) \cdot$ A. Tempia $\cdot$ N. Halkic Department of Visceral Surgery and Transplantation, University Hospital CHUV, Bugnon 46, 1012 Lausanne, Switzerland e-mail: demartines@chuv.ch

P. Allemann

e-mail: pierre.allemann@chuv.ch

H. Bouzourene

Department of Pathology, University Hospital CHUV,

Bugnon 46, 1012 Lausanne, Switzerland giant HCC group. There were no differences en terms of recurrence rate, pattern, and timing.

Conclusions Liver resection for HCC larger than $10 \mathrm{~cm}$ is a valuable option in selected patients, one that provides overall survival and disease-free survival comparable to smaller lesions. Functional reserves of the liver, more than the size of the lesion, may be important in patient selection for surgical resection.

\section{Introduction}

Among various factors, management guidelines for hepatocellular carcinoma (HCC) rely on the size of the lesion as a factor in selection of the most appropriate treatment. This approach is anchored in the Milan criteria [1] for liver transplantation and is also applied in other guidelines [2], to determine whether liver resection (LR), radiofrequency ablation (RFA), or transcatheter arterial chemoembolization (TACE) should be proposed for the treatment of individual HCC patients. The widespread use of size criteria to guide HCC treatment is based, among other factors, on the observation that both survival and risk for recurrence may be related to the size of the lesion [3-7], even if this approach has not been observed in some series $[8,9]$.

Although the management of HCC lesions larger than $5 \mathrm{~cm}$ continues to be debated, few data are available regarding giant $\mathrm{HCC}(\geq 10 \mathrm{~cm})$ [4-26], and are in most cases retrospective. Some investigators suggest that giant lesions represent more aggressive tumors [25] and are associated with higher rates of vascular invasion [7], which brings into question the value of surgery as a therapeutic option. However, adverse outcomes have not been observed in all studies [6, 20, 24]. Still, the lack of significant data may lead to confusion in the choice of 
therapeutic options. For example, RFA technology and results continue to improve, but experience with large tumors remains limited and the few available reports are confined to small series [25, 27-29]. Moreover, complete ablation of large lesion remains exceptional, due to the limitations of thermal diffusion volume and the frequent proximity of large blood vessels, factors that inhibit the effectiveness of RFA in these cases [30]. As consequence, RFA is currently proposed as palliative treatment [27-29], or is used in combination with resection [25]. Transcatheter arterial chemoembolization has been reported to be feasible in the treatment of giant HCC [31-34], but there are no published reports of complete cure, thus TACE is not validated as therapeutic approach in giant HCC. Finally, liver resection may be the only chance of cure in these patients [3-26], despite surgical limitations like liver size, functional reserve, and anatomical restrictions. In fact, radical surgery for giant HCC has been reported in some case series, but this approach remains controversial due to concerns regarding the potential aggressiveness of such tumors $[7,25]$ the high morbidity associated with major liver interventions-25\% to more than $50 \%$ in recent series $[4,16-19,23,26]$ - and a mortality rate ranging from 0 to $8 \%[4,7,16-19,21-26]$. These concerns are reflected in numerous international guidelines, which limit recommendations for liver resection to small tumors [2]. In contrast, recent Japanese guidelines used physiological criteria and liver remnant size, rather than tumor size, to determine the indications for liver resection in HCC [3537]. This difference in recommendations stems from the lack of data and reflects concerns regarding the long-term results of such aggressive management.

The goal of the present study was to analyze long-term survival and disease-free survival after liver resection for giant $\mathrm{HCC} \geq 10 \mathrm{~cm}$ compared to $\mathrm{HCC}<10 \mathrm{~cm}$ in diameter. Our hypothesis was that tumor size may not be the determinant for survival, thus allowing treatment of giant HCC by firstline surgery in selected patients.

\section{Patients and methods}

From 1 January 1997 to 31 December 2009, 311 consecutive patients with HCC were admitted to the Department of Digestive Surgery at the University Hospital of Lausanne, Switzerland. Of these 311 patients, 114 underwent liver resection with curative intent and constituted the study population (Fig. 1). All patients had a confirmed histological diagnosis of HCC, none of the fibrolamellar subtype. Thirteen patients were excluded from the analysis ( 2 had mixed tumor HCC-cholangiocarcinoma and 11 had incomplete data). The remaining 101 patients were categorized into two groups: patients with tumors less than
$10 \mathrm{~cm}$ in diameter (small HCC; $n=79$ ) and patients with tumors larger than $10 \mathrm{~cm}$ (giant $\mathrm{HCC} ; n=22$ ). For the giant $\mathrm{HCC}$ group, all histological findings were reviewed by an independent senior pathologist.

The preoperative work-up included blood tests, including alpha-fetoprotein and determination of values needed to calculate the CHILD score and the MELD score, dual radiology modalities (thoracoabdominal computed tomography $[\mathrm{CT}]$ and liver magnetic resonance imaging [MRI]) with liver volumetry. In addition, the indocyanine green retention (ICGR) test at $15 \mathrm{~min}$ and invasive portal pressure measurement were performed. Percutaneous biopsy was only considered in lesions with non-HCC-typical imaging. The management strategy for all patients was discussed during the weekly multidisciplinary hepatobiliary conferences, which included surgeons, radiologists, gastroenterologists, and pathologists.

Liver resection was the treatment proposed to all patients with a CHILD score of A or B, a MELD score less than 9 points, a remnant liver volume of at least $40 \%$, an ICGR test of less than $15 \%$ at $15 \mathrm{~min}$, and an invasive portal pressure of less than $10 \mathrm{mmHg}$.

After IRB approval from the Ethics Committee (University of Lausanne, Switzerland), an anonymized Excel database was constructed with patient demographic, operative data, pathological findings, and early follow-up data. A retrospective analysis of data was performed. The longterm outcomes were determined by telephone interviews with the attending physicians.

The primary endpoint was overall five-year survival, and the secondary endpoints were five-year disease-free survival, recurrence rate, perioperative mortality at 30 days, surgical complication rate, and reintervention rate.

Statistical analyses were performed with STATA software (Statacorp LP, College Station, TX) using Student's $t$ test for categorical data, the Mann-Whitney $U$ test for continuous data, and the Kaplan-Meier or log-rank test for survival analysis. The results were expressed as median and range. The cut-off for statistically significant outcome was a $p$ value less than 0.05 .

\section{Results}

Population characteristics and perioperative data

The demographic, histological, and operative data of the two groups are presented in Table 1. The two groups were homogeneously distributed in terms of age and preoperative American Society of Anesthesiologists (ASA) scores. There were significantly more patients with cirrhosis in the group with small HCC (77 vs. $41 \% ; p=0.0013$ ). In this group, four patients presented with Child-Pugh class B 
Fig. 1 Study flowchart

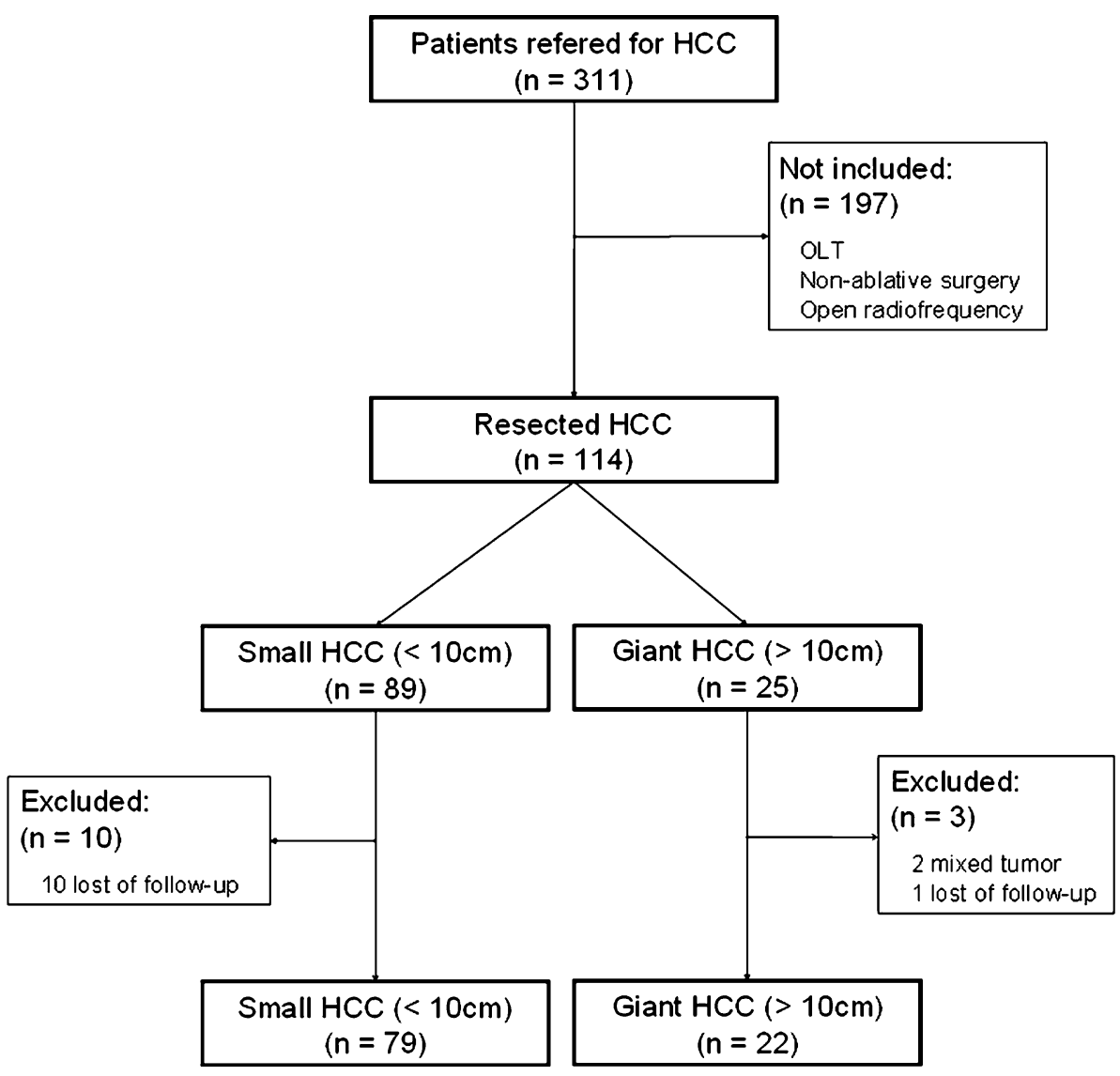

cirrhosis compared to none in the giant HCC group, where all patients presenting with cirrhosis were Child-Pugh class A. The cirrhosis etiologies were not different between the two groups apart from non-alcoholic non-viral causes (primary biliary cirrhosis and hemochromatosis), which were found more frequently in the small HCC group. The incidence of non-cirrhotic fibrotic liver disease did not differ statistically between the two populations.

The median number of liver segments resected per patient was statistically lower in the group with small HCC ( 3 vs. $4 ; p=0.005$ ), as was the rate of major hepatectomy, defined as more than three segments (51 vs. $76 \%$; $p=0.03$ ). Despite the differences in this feature of the operations, the operative time and the time of the Pringle maneuver were similar. After histological examination, the rate of $\mathrm{R} 0$ resection-defined as the absence of tumor in contact with the resection plane-was comparable in the two groups. In terms of staging, no differences were found between the small and giant HCC groups when comparing the grade of differentiation, the positive lymph node rate, and the rate of vascular invasion (microscopic or macroscopic). The median follow-up time was also similar in the two populations ( 24 vs. 25 months; $p=0.16$ ).

The follow-up data, and the immediate and long term postoperative data are presented in Table 2.
Immediate postoperative data

The 30-day mortality was not significantly different between the small and giant HCC groups ( 7 vs. $0 \%$; $p=0.14)$, but there was higher postoperative morbidity in the small HCC group (50 vs. $23 \% ; p=0.02)$. Liverrelated complications accounted for $57 \%$ in the small $\mathrm{HCC}$ group and $40 \%$ in the giant HCC group.

Survival

Results of the Kaplan-Meier analysis for overall survival are presented in Fig. 2. Both median survival (24 vs. 27 months; $p=0.0085$ ) and overall 5-year survival (21 vs. $45 \% ; p=0.04$ ) were significantly poorer in the small HCC group than in the giant HCC group.

\section{Recurrence}

Results of the Kaplan-Meier analysis for disease-free survival are presented in Fig. 3. The median disease-free survival for the two groups was not significantly different (10 vs. 15 months; $p=0.47$ ); as was the 5-year diseasefree survival (14 vs. $27 \% ; p=0.06$ ). The recurrence rate was identical in the two groups $(47 \%$ for the small HCC 
Table 1 Demographic, histological, and operative data for patients with small hepatocellular carcinoma and giant HCC

\begin{tabular}{|c|c|c|c|}
\hline & Small HCC $(n=79)$ & Giant HCC $(n=22)$ & $p$ Value \\
\hline Age, years (range) & $67(21-85)$ & $72(36-88)$ & 0.14 \\
\hline ASA score & 3 & 3 & 0.85 \\
\hline Cirrhosis, $n(\%)$ & $61(77)$ & $9(41)$ & $0.0013 *$ \\
\hline Fibrosis, $n(\%)$ & $6(7)$ & $3(14)$ & 0.46 \\
\hline \multicolumn{4}{|l|}{ Child-Pugh class, $n(\%)$} \\
\hline A & $75(95)$ & $22(100)$ & 0.08 \\
\hline $\mathrm{B}$ & $4(5)$ & $0(0)$ & $0.04 *$ \\
\hline $\mathrm{C}$ & $0(0)$ & $0(0)$ & - \\
\hline \multicolumn{4}{|l|}{ Etiology of cirrhosis, proportion (\%) } \\
\hline Alcoholic & $33 / 61(54)$ & $3 / 9(33)$ & 0.29 \\
\hline Hepatitis $\mathrm{C}$ virus & $13 / 61(21)$ & 2/9 (22) & 0.78 \\
\hline Hepatitis B virus & $10 / 61(16)$ & 4/9 (45) & 0.16 \\
\hline Other & $5 / 61(9)$ & $0 / 9(0)$ & $0.02 *$ \\
\hline Alpha fetoprotein (U/l) & $1921\left(5-50^{\prime} 500\right)$ & $2040\left(2-17^{\prime} 000\right)$ & 0.30 \\
\hline Segments resected, $n$ (range) & $3(1-5)$ & $4(1-6)$ & $0.005^{*}$ \\
\hline Major hepatectomy, $n(\%)$ & $40(51)$ & $17(76)$ & $0.03 *$ \\
\hline Operative time $(\min )$ & 199 & 215 & 0.31 \\
\hline Pringle maneuver, cumulative min & 30 & 31 & 0.71 \\
\hline R0 resection, $n(\%)$ & 77 (97) & $21(95)$ & 0.08 \\
\hline Tumor size, cm (\%) & $4.9(1-9)$ & $13.5(10-21)$ & - \\
\hline \multicolumn{4}{|l|}{ Tumor differentiation, $n(\%)$} \\
\hline Well & $38(48)$ & $7(33)$ & 0.40 \\
\hline Moderate & $29(37)$ & $9(40)$ & 0.42 \\
\hline Poor & $12(15)$ & $6(27)$ & 0.19 \\
\hline Positive lymph nodes, $n(\%)$ & $1(1)$ & $0(0)$ & 0.72 \\
\hline Vascular invasion by histology, $n(\%)$ & $13(16)$ & $2(9)$ & 0.33 \\
\hline
\end{tabular}

ASA American Society of Anesthesiologists

* Statistically significant $p<0.05$

Table 2 Patient outcomes

\begin{tabular}{|c|c|c|c|}
\hline Outcome & $\begin{array}{l}\text { Small HCC } \\
(n=79)\end{array}$ & $\begin{array}{l}\text { Giant HCC } \\
(n=22)\end{array}$ & $p$ Value \\
\hline $\begin{array}{l}\text { Follow-up, months } \\
\text { (range) }\end{array}$ & $24(1-186)$ & $25(2-164)$ & 0.16 \\
\hline $\begin{array}{l}\text { Median survival, months } \\
\text { (range) }\end{array}$ & $24(2-186)$ & $27(6-164)$ & $0.0085^{*}$ \\
\hline 5-Year survival $(\%)$ & 21 & 45 & $0.04 *$ \\
\hline $\begin{array}{l}\text { 5-Year disease-free } \\
\text { survival }(\%)\end{array}$ & 14 & 27 & 0.06 \\
\hline Recurrence, $n(\%)$ & $37(47)$ & $10(45)$ & 0.82 \\
\hline $\begin{array}{l}\text { Median recurrence time, } \\
\text { months (range) }\end{array}$ & $15(3-60)$ & $10(5-34)$ & 0.47 \\
\hline 30-Day mortality, $n(\%)$ & $6(7)$ & $0(0)$ & 0.14 \\
\hline Complication rate, $n(\%)$ & $40(50)$ & $5(23)$ & $0.02 *$ \\
\hline
\end{tabular}

$* p<0.05$

and $45 \%$ for the giant HCC group; $p=0.82$ ). In the group with small HCC, $10 \%$ of recurrences were local, $41 \%$ were hepatic recurrences at other locations, and $49 \%$ were

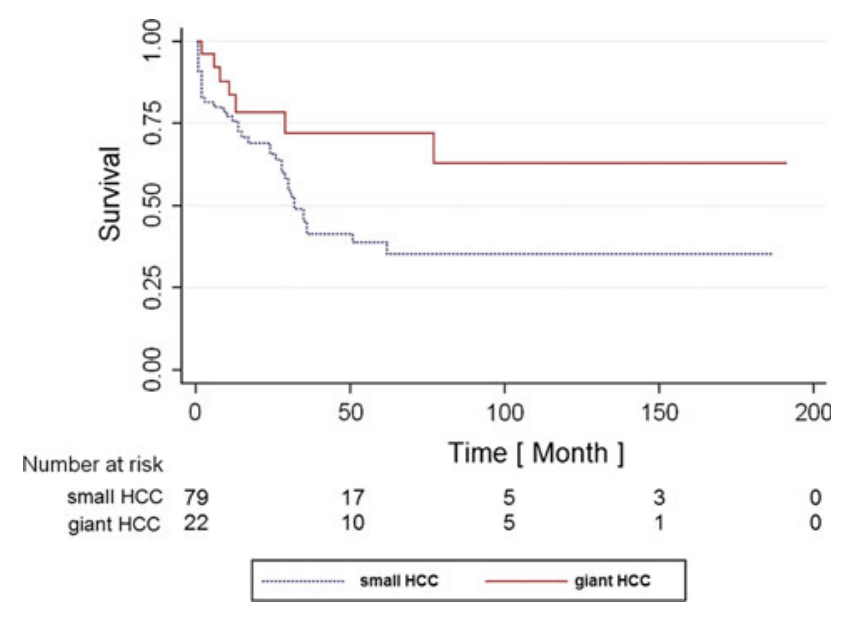

Fig. 2 Overall survival for giant hepatocellular carcinoma (HCC) versus small HCC (Kaplan-Meier analysis)

systemic recurrences (distant lymph nodes, lung, bone, and brain). In the group with giant $\mathrm{HCC}, 10 \%$ of recurrences were local, $10 \%$ were hepatic, and $80 \%$ were systemic 


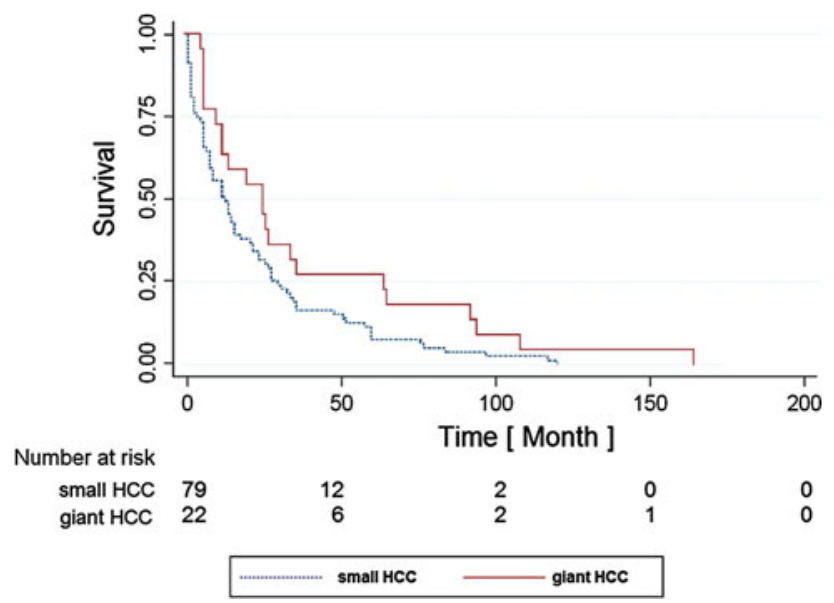

Fig. 3 Disease-free survival for giant $\mathrm{HCC}$ versus small HCC (Kaplan-Meier analysis)

recurrences (distant lymph nodes, lung). In patients with small HCC, $62 \%$ of the recurrences were treated with interventional radiology (RFA or TACE), and $22 \%$ underwent reoperation. In the group with giant $\mathrm{HCC}$, the corresponding figures were 20 and $20 \%$ for these interventions, respectively.

\section{Discussion}

Our results suggest that there is no outcome difference in surgery for giant HCC compared to smaller HCC, even if more complex surgery was performed in giant HCC.

In the present comparative retrospective study, we observed that overall survival, disease-free survival, and recurrence rates were similar after resection of giant $\mathrm{HCC}$ and resection of smaller lesions. This result strongly suggests that liver resection is an appropriate option for treating even very large lesions, as observed in other surgical series [4-26]. In giant HCC, surgery should probably be considered as firstline therapy, provided sufficient physiological liver reserves are available. Our results were concordant with those of Shah et al. [18] and Wang et al. [19], with 5-year survival rates reported to be as high as $50 \%$. However, it must be emphasized that the literature on this topic is somewhat confusing, with contradictory reports and some 5-year survival rates lower than $25 \%$ $[16,20,25]$.

In our own comparison, we observed that survival was significantly better in the giant HCC group. This is probably because our patient population in the giant HCC group included fewer patients with cirrhosis and no patients with CHILD B disease. Because of the limited sample size, we did not specifically analyze prognostic factors after resection of giant lesions, but, as observed in many other series
$[4,19,20,22]$, the presence of cirrhosis seems to influence negatively overall survival, regardless of the lesion size.

Having said that, this study was limited by the small sample size and the retrospective design, but this has been the case for the majority of other reports on giant HCC, and these limitations seem difficult to overcome, especially today, as primary liver resection is used less frequently in the management of HCC. However, with OLT and interventional radiology for small lesions, it seems that the number of patients with giant HCC referred for surgical consultation may be increasing, making understanding of such tumors more and more critical.

Another potential bias is the surgical nature of the present series, including good patient selection. Considering the small liver remnant, surgeons could have been negatively influenced, proposing interventions in patients who had a better functional reserve. Bearing in mind that the management strategy was proposed by a multidisciplinary board, it can be considered that this bias was minimized and that patient selection was adequate. Finally, patients with giant HCC may have had less aggressive tumors, as patients with advanced disease (bilateral involvement, extrahepatic disease, etc.) are less likely to be referred for surgical treatment. In addition, it is obvious that we did not compare our results to other treatment modalities like RFA or TACE, because of a lack of data and because these approaches have not been used to treat tumors larger than $10 \mathrm{~cm}$ in our center.

As in other studies [35-37], our results suggest that functional reserve of the remnant liver parenchyma, more than size of the lesion, may be important in patient selection for surgical resection. To assess and improve selection criteria, our patients underwent an extensive preoperative work-up that included indocyanine green retention time, invasive portal vein pressure, and liver volumetric evaluation.

To further improve the management of giant $\mathrm{HCC}$, more information about tumor biology and histology should be obtained. Key points like differentiation grade and the presence of vascular invasion have been reported to be associated with poor prognosis [3-5, 7, 15-18, 20-23, 26]. Interestingly however, we did not observe any differences between our two populations. This point is of importance, because the assumed aggressiveness of large HCC tumors represents for some investigators a clear limitation to surgery [38], which was not confirmed by our observations.

In conclusion, our results suggest that liver resection in the treatment of HCC larger than $10 \mathrm{~cm}$ is the best available therapeutic option in selected patients. A radical surgical approach may achieve good long-term survival and acceptable disease-free survival comparable to treatment of smaller lesions. 


\section{References}

1. Mazzaferro V, Regalia E, Doci R et al (1996) Liver transplantation for the treatment of small hepatocellular carcinomas in patients with cirrhosis. N Engl J Med 334:693-699

2. Llovet JM, Fuster J, Bruix J, Barcelona-Clínic Liver Cancer Group (2004) The Barcelona approach: diagnosis, staging, and treatment of hepatocellular carcinoma. Liver Transpl 10(Suppl 1):S115-S120

3. Yeh CN, Chen MF, Lee WC et al (2002) Prognostic factors of hepatic resection for hepatocellular carcinoma with cirrhosis: univariate and multivariate analysis. J Surg Oncol 81:195-202

4. Ng KK, Vauthey JN, Pawlik TM, International Cooperative Study Group on Hepatocellular Carcinoma et al (2005) Is hepatic resection for large or multinodular hepatocellular carcinoma justified? Results from a multi-institutional database. Ann Surg Oncol 12:364-373

5. Yamashita Y, Taketomi A, Shirabe K et al (2011) Outcomes of hepatic resection for huge hepatocellular carcinoma $(\geq 10 \mathrm{~cm}$ in diameter). J Surg Oncol 104:292-298

6. Choi GH, Han DH, Kim DH et al (2009) Outcome after curative resection for a huge $(\geq 10 \mathrm{~cm})$ hepatocellular carcinoma and prognostic significance of gross tumor classification. Am J Surg 198:693-701

7. Pawlik TM, Delman KA, Vauthey JN et al (2005) Tumor size predicts vascular invasion and histologic grade: implications for selection of surgical treatment for hepatocellular carcinoma. Liver Transpl 11:1086-1092

8. Verhoef C, de Man RA, Zondervan PE et al (2004) Good outcomes after resection of large hepatocellular carcinoma in the non-cirrhotic liver. Dig Surg 21:380-386

9. Young AL, Malik HZ, Abu-Hilal M et al (2007) Large hepatocellular carcinoma: time to stop preoperative biopsy. J Am Coll Surg 205:453-462

10. Ba MC, Cui SZ, Lin SQ et al (2010) Resection of a giant hepatocellular carcinoma weighing over ten kilograms. World J Gastroenterol 16:1422-1424

11. Korkolis DP, Aggeli C, Plataniotis GD et al (2009) Successful en bloc resection of primary hepatocellular carcinoma directly invading the stomach and pancreas. World J Gastroenterol 15:1134-1137

12. Hironori K, Masaru T, Yuichiro O et al (2008) Laparoscopyassisted hepatectomy for giant hepatocellular carcinoma. Surg Laparosc Endosc Percutan Tech 18:127-131

13. Miyoshi A, Takahashi T, Otsuka T et al (2009) Efficacy of major hepatectomy for large hepatocellular carcinoma. Hepatogastroenterology 56:768-772

14. Yang LY, Fang F, Ou DP et al (2009) Solitary large hepatocellular carcinoma: a specific subtype of hepatocellular carcinoma with good outcome after hepatic resection. Ann Surg 249:118-123

15. Pawlik TM, Poon RT, Abdalla EK, International Cooperative Study Group on Hepatocellular Carcinoma et al (2005) Critical appraisal of the clinical and pathologic predictors of survival after resection of large hepatocellular carcinoma. Arch Surg 140:450-457

16. Chen XP, Qiu FZ, Wu ZD et al (2006) Hepatectomy for huge hepatocellular carcinoma in 634 cases. World J Gastroenterol 12:4652-4655

17. Liau KH, Ruo L, Shia J et al (2005) Outcome of partial hepatectomy for large $(>10 \mathrm{~cm})$ hepatocellular carcinoma. Cancer 104:1948-1955

18. Shah SA, Wei AC, Cleary SP et al (2007) Prognosis and results after resection of very large $(\geq 10 \mathrm{~cm})$ hepatocellular carcinoma. J Gastrointest Surg 11:589-595
19. Wang CC, Jawade K, Yap AQ et al (2010) Resection of large hepatocellular carcinoma using the combination of liver hanging maneuver and anterior approach. World J Surg 34:1874-1878. doi:10.1007/s00268-010-0546-9

20. Wang J, Xu LB, Liu C et al (2010) Prognostic factors and outcome of 438 Chinese patients with hepatocellular carcinoma underwent partial hepatectomy in a single center. World J Surg 34:2434-2441. doi:10.1007/s00268-010-0664-4

21. Shimada K, Sakamoto Y, Esaki M et al (2008) Role of a hepatectomy for the treatment of large hepatocellular carcinomas measuring $10 \mathrm{~cm}$ or larger in diameter. Langenbecks Arch Surg 93:521-526

22. Pandey D, Lee KH, Wai CT et al (2007) Long-term outcome and prognostic factors for large hepatocellular carcinoma $(10 \mathrm{~cm}$ or more) after surgical resection. Ann Surg Oncol 14:2817-2823

23. Nagano Y, Tanaka K, Togo S et al (2005) Efficacy of hepatic resection for hepatocellular carcinomas larger than $10 \mathrm{~cm}$. World J Surg 29:66-71. doi:10.1007/s00268-004-7509-y

24. Zhou XD, Tang ZY, Ma ZC et al (2003) Surgery for large primary liver cancer more than $10 \mathrm{~cm}$ in diameter. J Cancer Res Clin Oncol 129:543-548

25. Mok KT, Wang BW, Lo GH et al (2003) Multimodality management of hepatocellular carcinoma larger than $10 \mathrm{~cm}$. J Am Coll Surg 197:730-738

26. Poon RT, Fan ST, Wong J (2002) Selection criteria for hepatic resection in patients with large hepatocellular carcinoma larger than $10 \mathrm{~cm}$ in diameter. J Am Coll Surg 194:592-602

27. Inagaki $\mathrm{H}$, Ito $\mathrm{N}$, Kurokawa $\mathrm{T}$ et al (2004) A case of giant hepatocellular carcinoma treatable with radio frequent ablation therapy after effective UFT administration. Gan To Kagaku Ryoho 31:1411-1414

28. Hirooka M, Koizumi Y, Kisaka Y et al (2010) Mass reduction by radiofrequency ablation before hepatic arterial infusion chemotherapy improved prognosis for patients with huge hepatocellular carcinoma and portal vein thrombus. AJR Am J Roentgenol 194:221-226

29. Sun WB, Ding XM, Ke S et al (2009) Repeated radiofrequency ablation as both salvage solution and curative treatment for spontaneous rupture of giant medial lobe hepatocellular carcinoma. Chin Med J (Engl) 122:2067-2070

30. Künzli BM, Abitabile P, Maurer CA (2011) Radiofrequency ablation of liver tumors: actual limitations and potential solutions in the future. World J Hepatol 3:8-14

31. Yajima Y, Miyazaki A, Miyasato S et al (1996) A case of giant hepatocellular carcinoma successfully treated by arterial administration of SMANCS. Gan To Kagaku Ryoho 23:1325-1329

32. Harada W, Kitamoto M, Hayashi R et al (2009) Large hepatocellular carcinoma successfully treated with transarterial chemoembolization using cisplatin. Nippon Shokakibyo Gakkai Zasshi 106:1189-1195

33. Huang YH, Wu JC, Chen SC et al (2006) Survival benefit of transcatheter arterial chemoembolization in patients with hepatocellular carcinoma larger than $10 \mathrm{~cm}$ in diameter. Aliment Pharmacol Ther 23:129-135

34. Zhou WP, Lai EC, Li AJ et al (2009) A prospective, randomized, controlled trial of preoperative transarterial chemoembolization for resectable large hepatocellular carcinoma. Ann Surg 249: 195-202

35. Uchiyama K, Mori K, Tabuse K et al (2008) Assessment of liver function for successful hepatectomy in patients with hepatocellular carcinoma with impaired hepatic function. J Hepatobiliary Pancreat Surg 15:596-602

36. Lau H, Man K, Fan ST et al (1997) Evaluation of preoperative hepatic function in patients with hepatocellular carcinoma undergoing hepatectomy. Br J Surg 84:1255-1259 
37. Ishizawa T, Hasegawa K, Aoki T et al (2008) Neither multiple tumors nor portal hypertension are surgical contraindications for hepatocellular carcinoma. Gastroenterology 134:1908-1916
38. Zhou L, Rui JA, Wang SB et al (2011) Prognostic factors of solitary large hepatocellular carcinoma: the importance of differentiation grade. Eur J Surg Oncol 37:521-525 